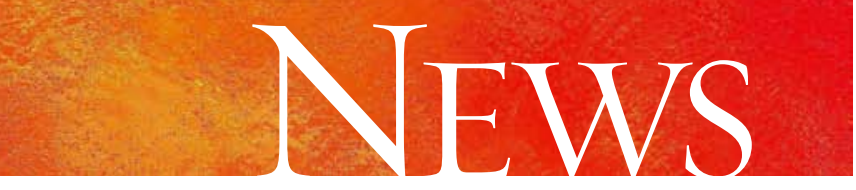

\title{
Privacy issues raised over Plan B: women asked for names,
}

\section{addresses, sexual history}

$\mathrm{T}$ he Canadian Pharmacists Association $(\mathrm{CPhA})$ is advising its members to collect women's names, addresses, and sensitive personal information before dispensing the emergency contraceptive levonorgestrel (Plan B) - a practice that is sounding alarms for women's organizations and privacy experts.

As levonorgestrel moved from being a prescription drug to a behind-thecounter medication in April 2005, the $\mathrm{CPhA}$ posted guidelines for pharmacists online (www.pharmacists.ca) on distributing the drug, including instructions on the need to counsel women and a form to guide this counselling (www.pharmacists.ca/content /about_cpha/Whats_Happening/CPhA _in_Action/pdf/ECP_PatientScreening FormForECPs.pdf). The CPhA also offered courses on how to counsel.

The form asks for personal data, including the woman's name, address, the date of her last menstrual period, when she had unprotected sex, and her customary method of birth control. Pharmacists are also asked to record the reason for dispensing the medication. The CPhA advises pharmacists to store the information in their computers, as they would with prescription data.

Pharmacists can charge a counselling fee for levonorgestrel, typically around $\$ 20$.

Health Canada made the drug available as a Schedule II non-prescription medication with the intention of increasing access, since levonorgestrel is most effective when used within 72 hours of unprotected intercourse.

Collecting this information, however, may create barriers, says the Canadian Women's Health Network, which believes that any retail outlet should be able to dispense levonorgestrel without mandatory coun- selling by a pharmacist. Women and teenage girls who need the contraceptive but are concerned about their privacy and the collection and storage of their data won't go to the pharmacy to get it, says Abby Lippman, chair of the Network and an epidemiologist at McGill University.

"It's an invasion of privacy," she says. "Why should we set up a situation where people have to hide or lie? Don't ask - you don't need to know."

A 26-year-old Saskatoon woman who was at risk of pregnancy told $C M A J$ that she expected her personal information would be kept confidential, "But it wasn't clear to me and I did$n$ 't understand the purpose of writing down my name." The woman, who requested anonymity, says she found the overall experience "really intimidating" and potentially a barrier to access.

The Network, which includes individuals, groups, organizations and institutions concerned with women's health, is also worried that the total cost of levonorgestrel will be a barrier to access. The cost ranges from $\$ 2 \mathrm{I}$ in Winnipeg, at a pharmacy that did not charge counselling fees, to $\$ 52$ in Vancouver where a pharmacy charged $\$ 25$ for counselling. Pharmacists pay $\$ 15.95$ to buy the drug wholesale.

BC Privacy Commissioner David Loukidelis questions why pharmacists in his province and across the country are recording and storing information about women who ask to buy the pills. "Where is it that pharmacists are getting the mandate in their view for collecting all of that personal information before dispensing the drug?" he asked in an interview with CMAJ.

"If there's no legislative requirement, and it's not convincingly or persuasively shown that there's a due diligence issue for them, then is that appropriate? I would have some very serious concerns about that. I would

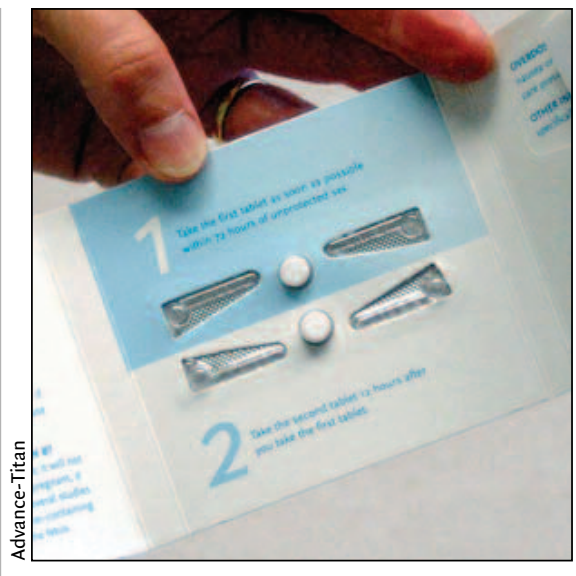

Requests for personal information may be a barrier to accessing emergency contraception, says the Canadian Women's Health Network.

strongly urge them to revisit this issue."

A basic principle of privacy codes is that no one should collect more information than they need, says Loukidelis. But that is exactly what the pharmacists are doing, argues the Canadian Women's Health Network.

In fact, it's not mandatory for pharmacists to collect women's names and addresses, says Janet Cooper, senior director of professional affairs for the $\mathrm{CPhA}$. The Association is not a regulatory body, and the guidelines for pharmacists, as well as the Emergency Contraceptive Pills (ECPs) training course it offers, are simply advisory, she says.

Pharmacists collect the information to determine if ECPs are appropriate, Cooper says. "In a fairly high percentage of cases, the woman comes in thinking she needs emergency contraception and in a consultation with pharmacists [realizes] she doesn't need it. Or it's a timing issue," Cooper says.

The counselling session also allows pharmacists to provide more information about contraception, she says.

A CPhA document (Emergency Contraception Questions and Answers for Pharmacists) released Apr. I9, 2005, the day that levonorgestrel be- 
came a Schedule II drug, states: "With some questioning the need for a pharmacist's intervention, the profession must step up to this opportunity and show Canadian women the value of their services. Otherwise, the call to have this available front store [sic] or in convenience stores will grow louder."

There may be perfectly valid reasons to bolster the role of pharmacists in the health care system, says Lippman, but not at the expense of women at risk of an unintended pregnancy. "Let's not take it out on the backs of women who are in the most vulnerable situation, at a very scary time," she adds. prove access to and awareness of emergency contraception," the Association said in the April ig document. The $\mathrm{CPhA}$ only consulted health care providers about the screening form, not users, says Cooper.

Pharmacists are health care providers, she stressed. "To ask someone for their name is not unreasonable. This is not a condom. This is a drug that just in April came off prescription status, and it's been deemed by others that it should be behind the counter, and it should have the intervention of a health care provider. Therefore you have to have a discussion with the pharmacists."

"...the profession must step up to this opportunity and show Canadian women the value of their services."

\section{Canadian Pharmacists Association}

Some pharmacists have chosen on their own to not request women's names and addresses, several told CMAJ. Others have chosen to not charge a counselling fee, although the CPhA's "ECP Readiness Checklist" advises them to "determine what your counselling fee will be."

"I actually don't see the benefit of taking their name," says Tracee Vickerman, a pharmacist in Whitehorse. "We ask for their name and address to start a file, but if they're not willing to give that, we don't push it, we still counsel them and give it to them."

In Charlottetown, pharmacist Paul Jenkins says he believes dispensing Plan B is "more of a service than an assessment." He does not charge a counselling fee.

The CPhA was a co-applicant in the procedure to remove Plan $B$ from Schedule I status, and worked with Paladin Labs Inc. (the Canadian distributor), the Society of Obstetricians and Gynaecologists of Canada, health professional associations including the Canadian Medical Association, and women's health organizations "to im-
But Lippman says that since levonorgestrel is safe, will not harm a fetus even if a woman is pregnant, and has no contraindications or serious adverse effects, all the information women would need could be contained in a printed handout.

"Women are pretty smart," says Lippman. "We don't need a pharmacist to count back on his or her fingers...."

Privacy expert Carole Lucock, a lawyer and project manager of a privacy and anonymity project at the University of Ottawa, says the data collection raises issues about potential barriers to reproductive choice, privacy and security.

"It raises security concerns, because we know, for example, abortion clinics have been subject to significant issues in connection with women going into those places and being able to be shielded from view. At a minimum the security of the information that's being taken should be given very high priority."

The $\mathrm{CPhA}$ is establishing "practice guidelines" that ask for the women's names, addresses and personal health information, says Lucock. "If pharmacists are not required by law to collect that information, then it should be a matter of choice for women and they should be very clearly entitled to make that choice."

"If it's not a strict requirement, women should be given the option of whether to consult and whether to give information to the people," says Lucock.

In St. John's, pharmacist Dave Rogers says he collects names and addresses, though some patients - primarily teenage girls - have been reluctant to provide them. "They worry that, ' $\mathrm{Oh}$, is my Mom going to come in and find out?"," Rogers says. "I tell them that everything is kept confidential." Rogers says he collects the information in case of future drug interactions. Asked if he told the girls that he would dispense it even if they didn't provide their name and address, he replied "No."

If women are uncomfortable with the practice, there are people to whom they can appeal, says Lucock.

"One option people do have is to contact their provincial privacy commissioners, both federally and provincially."

Given the increasing amount of personal information that various entities have on file about Canadians, this particular data collection also raised questions when $C M A J$ brought it to the attention of the office of Canada's federal privacy commissioner.

Pharmacists collecting this information should be telling women why they are doing so, what use they will make of the information, how long they are going to keep it, whether it will be disclosed to anyone else, and who they can complain to, says Heather Black, assistant privacy commissioner in Ottawa.

None of the 8 privacy commissioners or ombudsmen that $C M A J$ contacted had yet received complaints about the information collected by pharmacists. "We'd certainly look into it" if we got a complaint, said Irene Hamilton, Manitoba Ombudsman. - Laura Eggertson and Barbara Sibbald, $C M A J$

DOI:Io.I503/cmaj.05I46I 